\title{
Abuse, Outpatient Charges and Utilization, and Psychiatric Symptoms among Urban Women on Medicaid
}

\author{
John H. Porcerelli, PhD, Rosemary Cogan, PhD, Tsveti Markova, MD, \\ William Murdoch, MD, and Mary Anne Porcerelli, RN, MA
}

Background: Adult and childhood sexual and physical abuse are common and intertwined. Our objectives were to assess (1) the relationship between different forms of abuse; (2) outpatient charges and hospital and emergency department use among women with and without childhood and adult abuse; (3) psychiatric symptoms of women with and without childhood and adult abuse; and (4) the relationship between psychiatric symptoms and outpatient charges and hospital and emergency department use among a group of Medicaid-insured women seeking outpatient services in a primary care setting.

Methods: We recruited female primary care patients for this cross-sectional study. Women reported childhood and adult sexual and physical abuse and anxiety, depression, and posttraumatic stress symptoms. We assessed outpatient charges through reviews of clinic records. Patients reported hospital and emergency department use.

Results: Childhood and adult sexual and physical abuse were highly interrelated. Adult sexual abuse showed a trend toward significantly greater outpatient charges. Women who had experienced physical abuse during childhood had more emergency department visits and women who experienced physical abuse as an adult had more days of hospitalization. Childhood and adult sexual abuse were both related to higher levels of anxiety, depression, and posttraumatic stress symptoms. Anxiety, depression, and posttraumatic stress symptoms were related to higher outpatient charges. Depression and posttraumatic stress symptoms were related to greater emergency department use.

Conclusions: Women who experience abuse often have psychiatric symptoms. In our sample it was the severity of psychiatric symptoms rather than reported abuse alone that was related to outpatient charges and emergency department visits. (J Am Board Fam Med 2010;23:363-370.)

Keywords: Sexual Abuse, Physical Abuse, Adult, Child, Utilization, Symptoms, Psychiatry

Sexual and physical abuse among children and adults are common. During childhood, between

This article was externally peer reviewed.

Submitted 18 May 2009; revised 20 January 2010; accepted 25 January 2010.

From the Department of Family Medicine and Public Health Sciences, Wayne State University School of Medicine, Rochester, MI (JHP, TM, WM); Department of Psychology, Texas Tech University, Lubbock (RC); and Bloomfield Hills, MI (MAP).

Funding: This study was conducted with the support of federal matching funds through the Michigan Department of Community Health and Wayne State University Department of Family Medicine and Public Health Sciences (MDCH 224-23M2Q, 2005-2007). The grant was awarded to John H. Porcerelli.

Conflict of interest: none declared.

Corresponding author: John H. Porcerelli, PhD, Department of Family Medicine and Public Health Sciences, Wayne State University/Crittenton Family Medicine Residency Program, 1135 W. University Drive, Suite 250, Rochester Hills, MI 48307-1831 (E-mail: jporcer@med.wayne.edu).
$4 \%^{1}$ and $26.9 \%^{2}$ of girls experience sexual abuse and between $17 \%^{2}$ and $40 \%^{3}$ experience physical abuse. Between $1.7 \%^{4}$ and $25.6 \%^{5}$ of women have been sexually abused by their partners and between $1.1 \%^{6}$ and $30.6 \%^{3}$ have been physically abused during the past year. Women also experience abuse by nonpartners. Between $2.3 \%^{7}$ and $20.9 \%{ }^{8}$ of women have been physically abused by a nonpartner during the past year. Extremely high rates of childhood and adult abuse were reported in a sample of women seen at a Veteran's Affairs women's clinic, of whom $90 \%$ were veterans. $^{9}$ Of these women, $59 \%$ experienced sexual abuse during childhood, 39\% experienced sexual abuse as an adult, and 74\% experienced physical abuse by partners. Although the prevalence estimates differ for many reasons, one contributing factor is differences in the economic 
circumstances of the women in the samples; abuse rates are higher among low-income wom$\mathrm{en}^{10}$ and women receiving public assistance than among other women. ${ }^{11}$

Sexual abuse during childhood and sexual abuse as an adult are often interrelated, as is the experience of physical abuse during childhood and as an adult. ${ }^{3,4,12-14}$ Women with a history of both sexual and physical abuse as children are several times more likely than other women to experience sexual and physical abuse as adults. ${ }^{3}$ Abuse seems to lead to increased health care costs and mental health problems. Among more than 2000 women in a health care delivery system, women who experienced both sexual and physical abuse during childhood had higher use of mental health resources, emergency departments, hospitals, outpatient services, pharmacies, and specialty care than did women who experienced only sexual or only physical abuse. ${ }^{14}$ In several other large samples, outpatient costs were higher among women who were physically abused by their partners as compared with those who were not physically abused by a partner. ${ }^{5,15}$ In a comparison of women who experienced and women who did not experience physical abuse by partners, women who were physically abused by a partner had $\$ 1,775$ more in health costs during a sample year, with more hospitalizations and more use of outpatient clinics. ${ }^{16}$ Abuse during childhood is associated with depression among women as adults ${ }^{17}$ and lifetime abuse is associated with more anxiety and depression. ${ }^{2}$ Studies of abuse and health care costs have generally failed to take into account the impact of abuse on mental health.

\section{Methods}

Women were recruited for this study in the waiting room of an urban family medicine residency training clinic in a large Midwestern city. The clinic receptionist asked 161 consecutive Medicaid-insured women between the ages of 18 and 64 years of age who were caring for at least one child in their home if they would be willing to participate in the research project, which required coming to the clinic for a separate appointment; they were provided an $\$ 80$ honorarium for participation. A research team member (a social worker or psychologist) provided information about the study to the 143 women who said they might be willing to participate and scheduled an appointment. Each woman reviewed the consent and Health Insurance Portability and Accountability Act forms with the research team member. The study materials were complete for 97 women. The study was approved by both the Michigan Department of Community Health and the Wayne State University Institutional Review Board.

A demographic questionnaire included questions about age, race/ethnicity, marital status, education, employment, and income. Medical information was obtained through a detailed review of the women's medical charts and through self-report measures. Medical chart reviews were conducted by a licensed registered nurse.

Primary care (outpatient) charges were calculated for the past year and included the charges for each office visit plus the charges for laboratory tests ordered by the physician, as well as the charges for procedures performed during the visit (eg, electrocardiogram, spirometry). Charges were based on established evaluation and management criteria and the number of elements of history taking and physical examination and the complexity of decision making were taken into account.

Two questions were included about utilization. One concerned the total number of days spent in the hospital during the previous year and the other queried about emergency department visits during the previous year. These data were obtained from participant self-report using a 5-point Likert scale, ranging from 0 ("none") to 4 ("6 or more"), from the Multidimensional Health Profile-Health Index scale. ${ }^{18}$ This scale has good test-retest reliability and convergent validity.

The Childhood Trauma Questionnaire ${ }^{19}$ is a 28-item self-report measure of childhood abuse and neglect. Each of 5 types of experiences is assessed with 5 questions to which respondents respond using a scale ranging from 1 ("never true") to 5 ("very often true"). We used both the physical and sexual abuse subscales. The physical abuse scale included items such as, "I was punished with a belt, a board, a cord, or some other hard object." The sexual abuse scale includes items such as, "Someone molested me." We grouped physical abuse during childhood and sexual abuse during childhood into "none " versus "some."

The Conflict Tactics Scale (CTS) $2^{20}$ is a 66item self-report measure of conflict tactics others have directed to the respondent. The measure begins with a statement that, "No matter how well 
Table 1. Correlations between Outpatient Charges and Utilization and Symptoms of Anxiety, Depression, and Posttraumatic Stress Disorder

\begin{tabular}{|c|c|c|c|c|c|c|}
\hline \multirow[b]{2}{*}{ Symptoms } & \multicolumn{2}{|c|}{ Outpatient Charges } & \multicolumn{2}{|c|}{ Days Spent in Hospital } & \multicolumn{2}{|c|}{ Emergency Room Visits } \\
\hline & $r$ & $P$ & $r$ & $P$ & $r$ & $P$ \\
\hline Anxiety & 0.28 & .005 & 0.02 & .84 & 0.13 & .20 \\
\hline Depression & 0.29 & .004 & 0.11 & .30 & 0.31 & .002 \\
\hline PTSD & 0.29 & .004 & 0.12 & .25 & 0.24 & .02 \\
\hline
\end{tabular}

PTSD, Posttraumatic Stress Disorder.

people get along, there are times when they disagree ..." and noting that "People also have many ways of trying to settle their differences." The focus here is on responses to the 12-item Physical Assault scale and the 7-item Sexual Coercion scale. The physical abuse items range from mild (eg, "Threw something at me that could hurt") to severe (eg, "Choked me"). Responses ranged from 0 ("This has never happened") to 6 ("More than 20 times in the past year"). We scored an additional response, "Not in the past year, but it did happen before," as a 0 . The internal consistency reliability and the construct and discriminant validity of the CTS2 are good. ${ }^{20} \mathrm{We}$ included the CTS-Partners, on which respondents indicated how often they experienced each act by their partners, and the CTS-Others, on which respondents indicated how often they experienced each act by nonpartners. We grouped levels of physical and sexual abuse by partners and nonpartners into "none" or "some" during the past year.

The Patient Health Questionnaire ${ }^{21}$ (PHQ) is a self-report measure specifically developed for primary care practices. The PHQ assesses several psychiatric disorders/syndromes including somatoform disorder, major depressive syndrome, other depressive syndromes, other anxiety syndrome, panic disorder, alcohol abuse, and binge eating disorders. For the present study we considered the major depression and anxiety scales. The major depression scale included 9-items scored on a 4-point scale; the patient indicated how often a symptom has bothered them within the last 2 weeks, ranging from 0 ("not at all") to 3 ("nearly every day"), and the scale total can range from 0 to 27. The anxiety syndrome scale included 7-items scored on a 3-point scale; patients indicated how often a symptom has bothered them within the last 4 weeks, ranging from 0 ("not at all") to 2 ("more than half the days"), and the scale total can range from 0 to 14 . The validity of the PHQ has been supported by studies from primary care ${ }^{21}$ and ob-

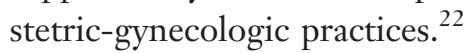

The Posttraumatic Stress Disorder Checklist (Civilian Version ${ }^{23}$ PCL-C) is a 17 -item self-report measure for assessing Posttraumatic Stress Disorder (PTSD). The 17 symptoms of PTSD from the Diagnostic and Statistical Manual of Mental Disorders, Fourth Edition, are grouped under 3 symptom clusters: intrusion, avoidance, and hyperarousal. Participants rate the severity of each item during the past 30 days on a 5-point scale, ranging from 0 ("not at all") to 4 ("extremely"). The PCL-C is a reliable and valid instrument. ${ }^{24}$ Convergent validity has been demonstrated through a correlation of 0.93 between the total PCL score and the Clinician-Administered PTSD Scale, ${ }^{25}$ with a diagnostic efficiency of 0.90 versus the Clinician-Administered PTSD Scale. Total PTSD scores could range from 0 to 68 .

Chi-square tests were used to assess the occurrence of the presence or absence of childhood and adult sexual and physical abuse and the occurrence of chronic illness among women who did or did not experience childhood and adult sexual and physical abuse. Factorial analysis of variance tests were conducted, with childhood sexual abuse (yes versus no) and adult sexual abuse (yes versus no) used as the factors and total outpatient charges, number of hospital days, number of emergency visits, anxiety, depression, and PTSD used as dependent variables. Factorial analysis of variance tests were conducted as well, with childhood physical abuse (yes versus no) and adult physical abuse (yes versus no) as the factors and using the same dependent variables as in the tests of sexual abuse. Finally, Pearson correlations were calculated between outpatient charges, hospital days, and emergency room visits and anxiety, depression, and PTSD symptoms. 
Table 2. Patient Demographics $(n=97)$

\begin{tabular}{lc}
\hline Age, years (mean [SD]) & $34.6(9.2)$ \\
Race/ethnicity (\%) & 91.8 \\
Black & 3.1 \\
White & 5.2 \\
Other & \\
Education (\%) & 24.7 \\
Some high school & 30.9 \\
High school graduate or GED & 41.2 \\
Some college & 3.1 \\
College graduate & \\
Marital status $(\%)$ & 11.3 \\
Married & 48.4 \\
Single & 30.9 \\
Separated/divorced & 9.3 \\
Other & \\
Income (\%) & 54.6 \\
$<\$ 10,000$ & 29.9 \\
\$10,000-\$24,999 & 11.3 \\
\$25,000-\$49,999 & 4.1 \\
$\geq \$ 50,000$ & \\
Employed outside the home (\%) & 25.8 \\
Unemployed & 17.5 \\
Work part time & 38.2 \\
Work full time & 17.5 \\
Other & 48.0 \\
\hline
\end{tabular}

GED, general educational development test.

Each of these 6 variables was within limits of skewness and kurtosis for a normal distribution ${ }^{26}$; the correlations are show in Table 1 .

\section{Results}

The demographic characteristics of the 97 women are shown in Table 2. Forty-three percent of the women reported childhood sexual abuse and $47 \%$ reported childhood physical abuse. Both childhood sexual and childhood physical abuse were reported by $36 \%$ of the women. Thirty-one percent reported adult sexual abuse and $47 \%$ reported adult physical abuse had occurred during the past year. Both adult sexual and adult physical abuse were reported by $28 \%$ of the women. Women who were sexually abused as children more often experienced sexual abuse $\left(\chi^{2}=12.61, P=.0004\right)$ and physical abuse $\left(\chi^{2}=7.85, P=.005\right)$ as an adult than did women who were not sexually abused as children. Women who were physically abused as children also more often experienced sexual abuse $\left(\chi^{2}=8.88\right.$, $P=.003)$ and physical abuse $\left(\chi^{2}=3.34, P=.07\right)$ as an adult than did women who were not physically abused as children, as shown in Table 3.

Chronic illness was reported by $48 \%$ of the women. Chronic illness did not differ between women who experienced or did not experience sexual abuse as a child $\left(\chi^{2}=0.02 ; P=.89\right)$, physical abuse as a child $\left(\chi^{2}=0.01 ; P=.91\right)$, sexual abuse as an adult $\left(\chi^{2}=1.24 ; P=.26\right)$, or physical abuse as an adult $\left(\chi^{2}=0.30 ; P=.58\right)$.

Adult sexual abuse, but not childhood sexual abuse, tended to be related to outpatient charges. Sexual abuse both during childhood and as an adult were related to higher scores of anxiety, depression, and PTSD. These data are shown in Table 4. Adult physical abuse was related to more days spent in the hospital and childhood physical abuse was related to more emergency department visits. Both childhood and adult physical abuse were related to higher scores of anxiety and depression. Experience of physical abuse during childhood or physical abuse as an adult was not related to outpatient charges or PTSD. These data are shown in Table 5.

Table 3. Physical and Sexual Abuse during Childhood in Relation to Physical and Sexual Abuse as an Adult

\begin{tabular}{|c|c|c|c|c|c|}
\hline & \multicolumn{2}{|c|}{ Childhood Sexual Abuse } & \multicolumn{2}{|c|}{ Childhood Physical Abuse } & \multirow[b]{2}{*}{ Total } \\
\hline & No & Yes & No & Yes & \\
\hline \multicolumn{6}{|c|}{ Adult sexual abuse } \\
\hline No & $46(47)$ & $21(22)$ & $42(43)$ & $25(26)$ & $67(69)$ \\
\hline Yes & $9(9)$ & $21(22)$ & $9(9)$ & $21(22)$ & $30(31)$ \\
\hline \multicolumn{6}{|c|}{ Adult physical abuse } \\
\hline No & $31(32)$ & $11(11)$ & $27(28)$ & $15(15)$ & $42(43)$ \\
\hline Yes & $24(25)$ & $31(32)$ & $24(25)$ & $31(32)$ & $55(57)$ \\
\hline Total & $55(57)$ & $42(43)$ & $51(53)$ & $46(47)$ & $97(100)$ \\
\hline
\end{tabular}

All values provided as $\mathrm{n}(\%)$. 
Table 4. Health Charges and Utilization and Anxiety, Depression and Posttraumatic Stress Disorder Symptoms of Women Who Experienced or Did Not Experience Childhood and Adult Sexual Abuse

\begin{tabular}{|c|c|c|c|c|c|c|c|c|c|c|}
\hline & \multirow{2}{*}{\multicolumn{3}{|c|}{ Childhood Sexual Abuse (mean [SD]) }} & \multicolumn{7}{|c|}{$2 \times 2$ Factorial ANOVA Test Results } \\
\hline & & & & \multicolumn{2}{|c|}{$\begin{array}{c}\text { Childhood } \\
\text { (C) }\end{array}$} & \multicolumn{2}{|c|}{ Adult (A) } & \multicolumn{2}{|c|}{$\mathrm{C}^{*} \mathrm{~A}$} & \multirow[b]{2}{*}{$\mathrm{R}^{2}$} \\
\hline & No & Yes & Total & $\mathrm{F}$ & $P$ & $\mathrm{~F}$ & $P$ & $\mathrm{~F}$ & $P$ & \\
\hline \multicolumn{11}{|l|}{ Total outpatient charges } \\
\hline No adult sexual abuse & $535(453)$ & $588(346)$ & $552(421)$ & & & & & & & \\
\hline Adult sexual abuse & $703(460)$ & $844(508)$ & $802(491)$ & & & & & & & \\
\hline Total & $563(455)$ & $716(449)$ & $629(456)$ & 0.60 & .44 & 3.40 & .07 & 0.03 & .86 & \\
\hline \multicolumn{11}{|l|}{ Days spent in hospital (n) } \\
\hline No adult sexual abuse & $1.3(0.9)$ & $1.5(0.9)$ & $1.4(0.9)$ & & & & & & & \\
\hline Adult sexual abuse & $1.7(1.1)$ & $1.8(1.1)$ & $1.7(1.1)$ & & & & & & & \\
\hline Total & $1.4(0.9)$ & $1.6(1.0)$ & $1.5(1.0)$ & 0.24 & .63 & 1.74 & .19 & 0.01 & .94 & \\
\hline \multicolumn{11}{|l|}{$\mathrm{ER}$ visits (n) } \\
\hline No adult sexual abuse & $2.1(1.2)$ & $2.5(1.1)$ & $2.2(1.2)$ & & & & & & & \\
\hline Adult sexual abuse & $2.6(0.9)$ & $2.4(1.3)$ & $2.5(1.2)$ & & & & & & & \\
\hline Total & $2.2(1.2)$ & $2.5(1.2)$ & $2.3(1.2)$ & 0.18 & .67 & 0.49 & .49 & 0.75 & .39 & \\
\hline \multicolumn{11}{|l|}{ Anxiety } \\
\hline No adult sexual abuse & $2.6(3.4)$ & $5.2(4.5)$ & $3.4(3.9)$ & & & & & & & \\
\hline Adult sexual abuse & $6.0(5.0)$ & $7.5(4.2)$ & $7.0(4.5)$ & & & & & & & \\
\hline Total & $3.1(3.8)$ & $6.4(4.4)$ & & 4.8 & .03 & 8.9 & .004 & 0.40 & .53 & 0.21 \\
\hline \multicolumn{11}{|l|}{ Depression } \\
\hline No adult sexual abuse & $4.3(4.8)$ & $8.9(6.0)$ & $4.9(5.4)$ & & & & & & & \\
\hline Adult sexual abuse & $8.4(7.3)$ & $12.6(6.7)$ & $10.7(6.5)$ & & & & & & & \\
\hline Total & $5.7(5.6)$ & $11.3(7.0)$ & & 10.10 & .002 & 8.28 & .005 & 0.03 & .86 & 0.26 \\
\hline \multicolumn{11}{|l|}{ PTSD } \\
\hline No adult sexual abuse & $11.4(11.9)$ & $20.3(16.3)$ & $13.5(14.0)$ & & & & & & & \\
\hline Adult sexual abuse & $24.4(19.1)$ & $31.1(18.8)$ & $25.7(18.2)$ & & & & & & & \\
\hline Total & $14.2(14.0)$ & $29.1(18.8)$ & & 4.57 & .04 & 10.67 & .002 & 0.10 & .75 & 0.22 \\
\hline
\end{tabular}

ANOVA, analysis of variance; ER, emergency room; PTSD, Posttraumatic Stress Disorder.

Higher outpatient charges were significantly correlated with anxiety, depression, and PTSD. More emergency room visits were related to depression and PTSD severity. Days spent in a hospital were not related to the severity of anxiety, depression, or PTSD.

\section{Discussion}

With this sample of urban-dwelling, Medicaid-insured women, we provide additional support for others' findings that sexual and physical abuse during childhood and as adults frequently occur together. That is, women who were sexually abused during childhood were very often physically abused as well, and women who were sexually abused during the past year were very often physically abused as well. Studies of violence need to take into account both types of abuse, and clinicians working with women need to be aware that if sexual abuse has occurred physical abuse is likely to have occurred as well. Consistent with the literature, women who were sexually abused as children were more likely than other women to have been sexually abused as adults, and women who were physically abused as children were more likely than other women to have been physically abused during the past year.

Although women with a history of sexual abuse during childhood and/or as an adult had higher health care charges, the differences were not statistically reliable. Only adult sexual abuse showed a trend toward significantly greater outpatient charges $(P=.07)$. Interestingly, the presence of sexual abuse did not impact the number of days spent in a hospital or the number of emergency room visits of these women. Childhood and adult 
Table 5. Health Charges and Utilization and Anxiety, Depression, and Posttraumatic Stress Disorder Scores of Women Who Experienced and Did Not Experience Childhood and Adult Physical Abuse

\begin{tabular}{|c|c|c|c|c|c|c|c|c|c|c|}
\hline & \multirow{2}{*}{\multicolumn{3}{|c|}{ Childhood Physical Abuse }} & \multicolumn{7}{|c|}{$2 \times 2$ Factorial ANOVA Test Results } \\
\hline & & & & \multicolumn{2}{|c|}{$\begin{array}{l}\text { Childhood } \\
\text { (C) }\end{array}$} & \multicolumn{2}{|c|}{ Adult (A) } & \multicolumn{2}{|c|}{$\mathrm{C}^{*} \mathrm{~A}$} & \multirow[b]{2}{*}{$\mathrm{R}^{2}$} \\
\hline & No & Yes & Total & $\mathrm{F}$ & $P$ & $\mathrm{~F}$ & $P$ & $\mathrm{~F}$ & $P$ & \\
\hline \multicolumn{11}{|l|}{ Total outpatient charges } \\
\hline No adult physical abuse & $459(400)$ & $660(407)$ & $601(467)$ & & & & & & & \\
\hline Adult physical abuse & 749 (494) & $660(471)$ & $660(447)$ & & & & & & & \\
\hline Total & $532(410)$ & $700(479)$ & & 0.36 & .55 & 2.33 & .13 & 2.33 & .13 & \\
\hline \multicolumn{11}{|l|}{ Days spent in hospital (n) } \\
\hline No adult physical abuse & $1.1(0.4)$ & $1.3(0.7)$ & $1.2(0.6)$ & & & & & & & \\
\hline Adult physical abuse & $1.8(1.2)$ & $1.7(1.0)$ & $1.7(1.1)$ & & & & & & & \\
\hline Total & $1.4(1.0)$ & $1.6(1.0)$ & & 0.12 & .73 & 6.30 & .01 & 0.58 & .45 & 0.08 \\
\hline \multicolumn{11}{|l|}{ ER visits (n) } \\
\hline No adult physical abuse & $1.8(1.1)$ & $2.7(1.0)$ & $2.1(1.1)$ & & & & & & & \\
\hline Adult physical abuse & $2.4(1.2)$ & $2.5(1.3)$ & $2.4(1.2)$ & & & & & & & \\
\hline Total & $2.1(1.2)$ & $2.5(1.2)$ & & 3.99 & .05 & 0.56 & .56 & 2.23 & .14 & 0.07 \\
\hline \multicolumn{11}{|l|}{ Anxiety } \\
\hline No adult physical abuse & $2.0(2.4)$ & $4.4(4.6)$ & $2.9(3.5)$ & & & & & & & \\
\hline Adult physical abuse & $4.8(4.3)$ & $6.4(4.8)$ & $5.7(4.6)$ & & & & & & & \\
\hline Total & $3.4(3.7)$ & $5.8(4.8)$ & & 5.13 & .03 & 7.69 & .007 & 0.20 & .65 & 0.15 \\
\hline \multicolumn{11}{|l|}{ Depression } \\
\hline No adult physical abuse & $3.2(3.6)$ & $7.6(5.4)$ & $4.8(4.8)$ & & & & & & & \\
\hline Adult physical abuse & $8.0(6.5)$ & $10.5(7.3)$ & $9.4(7.0)$ & & & & & & & \\
\hline Total & $5.5(5.7)$ & $9.6(6.8)$ & & 7.54 & .007 & 9.18 & .003 & 0.53 & .47 & 0.19 \\
\hline \multicolumn{11}{|l|}{ PTSD } \\
\hline No adult physical abuse & $10.2(8.3)$ & $18.0(17.1)$ & $13.0(12.7)$ & & & & & & & \\
\hline Adult physical abuse & $20.9(16.7)$ & $24.8(20.0)$ & $23.0(18.6)$ & & & & & & & \\
\hline Total & $15.4(14.1)$ & $22.6(19.2)$ & & 2.94 & .09 & 6.54 & .01 & 0.33 & .57 & 0.11 \\
\hline
\end{tabular}

ANOVA, analysis of variance; ER, emergency room; PTSD, Posttraumatic Stress Disorder.

sexual abuse were each related to higher levels of anxiety, depression, and PTSD. With regard to the effects of physical abuse, women with childhood physical abuse had more emergency room visits $(P=.05)$ and women with adult physical abuse spent more days in a hospital $(P=.01)$. Childhood and adult physical abuse were related to higher levels of anxiety, depression, and PTSD. Our findings suggest that it is the impact of abuse on mental health-not the abuse alone-that leads to greater outpatient health care charges and utilization of services.

Depression, anxiety, and PTSD severity were each related to total outpatient charges. There are many pathways to symptom severity, only one of which is abuse. Being a single mother with limited education, income, and employment are among the stressors in our sample and among Medicaid-insured, urban-dwelling women in general.
The discrepancy between the lack of differences in outpatient charges between the groups and the findings of others may be a function of sample size. Further, these women were insured by Medicaid and thus had limited financial resources; the lack of differences may reflect the well-documented effect of socioeconomic status on overall health. ${ }^{27}$

There are two important clinical implications for family physicians. First, if a patient presents with significant symptoms of anxiety, depression, or PTSD, a thorough abuse history may be warranted to provide comprehensive health care for women. A detailed abuse history may aid clinicians in understanding the patient and the dynamics of the doctor-patient relationship. For example, a depressed or anxious patient with a history of abuse may present with a heightened or magnified presentation of her current illness and may require extra sensitivity on part of the physician so that the 
physician and patient can work together collaboratively. Our data show that patients with a history of abuse are vulnerable to revictimization and the physician can help educate patients and can provide counseling about safety management. Second, for women with histories of abuse, assessment and treatment of depression, anxiety, and PTSD symptoms may help to reduce health care charges.

The most salient limitation of the present work is sample size. In addition, we do not have information about any care that that the women may have sought at other clinics. We do not have the charges of the days spent in a hospital and emergency room visits. Further, the number of days spent in a hospital and emergency room visits were obtained through self-report only. Despite these limitations, our results clearly show the comorbidity of childhood and adult abuse, that both types of abuse are associated with psychiatric symptom severity, and that outpatient charges are most directly associated with psychiatric symptom severity.

\section{References}

1. Seedat S, Stein MB, Forde DR. Association between physical partner violence, posttraumatic stress, childhood trauma, and suicide attempts in a community sample of women. Violence Vict 2005;20:87-98.

2. Ramos BM, Carlson BE, McNutt L. Lifetime abuse, mental health, and African American Women. J Fam Violence 2004;19:153-64.

3. Desai S, Arias I, Thompson MP, Basile KC. Childhood victimization and subsequent adult revictimization assessed in a nationally representative sample of women and men. Violence Vict 2002;17:639-53.

4. Romans S, Forte T, Cohen MM, DuMont J, Hyman I. Who is most at risk for intimate partner violence? J Interpers Violence 2007;22:1495-514.

5. Coker AL, Reeder CE, Fadden MK, Smith PH. Physical partner violence and Medicaid utilization and expenditures. Public Health Rep 2004;119:53767.

6. Tjaden P, Thoennes N. Prevalence and consequences of male-to-female and female-to-male partner violence as measured by the National Violence Against Women Survey. Violence Against Women 2000;6:142-61.

7. Porcerelli JH, Cogan R, West PP, et al. Violent victimization of women and men: physical and psychiatric symptoms. J Am Board Fam Pract 2003;16: 32-9.

8. Cogan R, Ballinger BC III. Alcohol problems and the differentiation of partner, stranger, and general violence. J Interpers Violence 2006;21:924-36.

9. Campbell R, Greeson MR, Bybee D, Raja S. The co-occurrence of childhood sexual abuse, adult sexual assault, intimate partner violence, and sexual harassment: a meditational model of posttraumatic stress disorder and physical health outcomes. J Consult Clin Psychol 2008;76:194-207.

10. Taft CT, Bryant-Davis T, Woodward HE, Tillman $\mathrm{S}$, Jones SE. Intimate partner violence against African American women: an examination of the sociocultural context. Aggress Violent Behav 2000;14:50-8.

11. Moracco KE, Runyan CW, Bowling JM, Earp JAL. Women's experiences with violence: a national study. Women's Health Issues 2007;17:3-12.

12. Classen CC, Palesh OG, Aggarwal R. Sexual revictimization: a review of the empirical literature. Trauma Violence Abuse 2005;6:103-29.

13. Breitenbecher KH. Sexual revictimization among women: a review of the literature focusing on empirical investigations. Aggress Violent Behav 2001;6: 415-32.

14. Bonomi AE, Anderson ML, Rivara FP, et al. Health care utilization and costs associated with child abuse. J Gen Intern Med 2008;23:294-99.

15. Rivara FP, Anderson ML, Fishman P, et al. Healthcare utilization and costs for women with a history of intimate partner violence. Am J Prev Med 2007;32: 89-96.

16. Wisner CL, Gilmer TP, Saltzman LE, Zink TM. Intimate partner violence against women: do victims cost health plans more? J Fam Pract 1999;48:439_ 43.

17. Chapman DP, Whitfield CL, Felitti VJ, Dube SR, Edwards VJ, Anda RF. Adverse childhood experiences and the risk of depressive disorders in adulthood. J Affect Disord 2004;82:217-25.

18. Karoly P, Ruehlman LS, Lanyon RI. The assessment of adult health care orientations: development and preliminary validation of the Multidimensional Health Profile-Health Functioning Index (MHP-H) in a national sample. J Clin Psychol Med Settings 2005;12:79-91.

19. Bernstein DP, Fink L. Childhood Trauma Questionnaire. San Antonio, TX: Psychological Corporation; 1998.

20. Straus MA, Hamby SL, Boney-McCoy S. The revised conflict tactics scale (CTS2): development and preliminary psychometric data. J Fam Issues 1996; 17:283-16.

21. Spitzer RL, Kroenke K, Williams JBW. Validation and utility of a self-report version of PRIME-MD. JAMA 1999;282:1737-44.

22. Spitzer RL, Williams JBW, Kroenke K, Hornyak R, McMurray J. Validity and utility of the PRIME-MD Patient Health Questionnaire in assessment of 3000 obstetric-gynecologic patients. The PRIME-MD Patient Health Questionnaire Obstetrics-Gynecologic study. Am J Obstet Gynecol 2000;183:759-69.

23. Weathers F, Litz B, Herman D, Huska J, Keane T. The PTSD Checklist (PCL): reliability, validity, and 
diagnostic utility. Paper presented at the Annual Convention of the International Society for Traumatic Stress Studies, San Antonio, TX. October 1993.

24. Walker EA, Newman E, Dobie DJ, Ciechanowski P, Katon WJ. Validation of the PTSD Checklist in an HMO sample of women. Gen Hosp Psychiat 2002; 24:375-80.

25. Blanchard EB, Jones-Alexander J, Buckley TC, Forneris CA. Psychometric properties of the PTSD Checklist (PCL). Behav Res Ther 1996;34:669-73.
26. Curran PJ, West SG, Finch JF. The robustness of test statistics to nonnormality and specification error in confirmatory factor analysis. Psych Rep 1996;1: 16-29.

27. Robert SA, Cherepanov D, Palta M, Dunham NC, Feeny D, Fryback DG. Socioeconomic status and age variations in health-related quality of life: results from the national health measurement study. J Gerontol B Psychol Sci Soc Sci 2009;64: $378-89$. 